TABLE 2. Comparison of clinical data, auditory perception (in decibels) according to the studied frequency of the sound, speech recognition threshold and tympanometry in SLE patients using and not using antimalarials

\begin{tabular}{lccc}
\hline & $\begin{array}{c}\text { With antimalarials } \\
\mathrm{N}=74 \text { ears }\end{array}$ & $\begin{array}{c}\text { Without } \\
\text { antimalarials } \\
\mathrm{N}=12 \text { ears }\end{array}$ & $\mathrm{P}$ \\
\hline Mean Age (years) (SD) & $46.4 \pm 12.7$ & $40.9 \pm 13.9$ & 0.22 \\
Median Disease duration & $8.50(5.00-14.25)$ & $12.00(8.25-21.25)$ & 0.19 \\
(years) & & & \\
MAC & $8.75(5.00-13.75)$ & $8.75(5.31-13.44)$ & 0.63 \\
AC $250 \mathrm{~Hz}$ & $10.00(5.00-18.75)$ & $10.00(5.00-15.00)$ & 0.81 \\
AC $500 \mathrm{~Hz}$ & $10.00(5.00-10.00)$ & $7.50(5.00-15.00)$ & 0.63 \\
AC $1.000 \mathrm{~Hz}$ & $5.00(0-10.00)$ & $2.50(0-10.00)$ & 0.47 \\
AC $2.000 \mathrm{~Hz}$ & $5.00(3.75-15.00)$ & $10.00(0-15,0)$ & 0.64 \\
AC $3.000 \mathrm{~Hz}$ & $10.00(5.00-15.00)$ & $12.50(5.00-18.75)$ & 0.43 \\
AC $4.000 \mathrm{~Hz}$ & $10.00(5.00-20.00)$ & $15.00(7.50-20.00)$ & 0.39 \\
AC $6.000 \mathrm{~Hz}$ & $12.50(5.00-21.25)$ & $20.00(15.00-25.00)$ & 0.07 \\
AC $8.000 \mathrm{~Hz}$ & $10.00(8.75-25.00)$ & $22.50(16.25-33.75)$ & 0.03 \\
SRT (\%) & $96.00(96.00-$ & $96.00(96.00-$ & 0.50 \\
& $100.00)$ & $100.00)$ & \\
TIMP & $0(0-0)$ & $0(0-0)$ & 0.99 \\
Tinnitus & $15 / 37(40.5 \%)$ & $4 / 6(66.6 \%)$ & 0.38 \\
Subjective hearing loss & $10 / 37(27.0 \%)$ & $1 / 6(16.6 \%)$ & 1.00 \\
Vertigo & $4 / 37(10.8 \%)$ & $2 / 6(33.3 \%)$ & 0.18 \\
\hline
\end{tabular}

Between parenthesis - interquartile rate; $n=$ number; $A C=$ airway conduction; $\mathrm{MAC}=$ mean airway conduction; $\mathrm{SRT}=$ speech recognition threshold; $\mathrm{TIMP}=$ tympanometry.

Disclosure of Interests: None declared

DOI: 10.1136/annrheumdis-2019-eular.5998

\section{AB0508 $\quad$ SCHIRMER TEST, VAN BIJSTERVELD, OSS, AND BREAK-UP TIME TEST IN PRIMARY SJOGREN'S SYNDROME}

Tania Fidelix ${ }^{1}$, Virginia Fernandes Moça Trevisani ${ }^{2}$, Laura Santos ${ }^{2}$, Denise Freitas ${ }^{2}$, Luiz Antonio Vieira ${ }^{2}$, Moacyr Rigueiro ${ }^{3} .{ }^{1}$ UNIFESP, OPHTHALMOLOGY, SAO PAULO, Brazil; ${ }^{2}$ UNIFESP, OPHTHALMOLOGY, sao paulo, Brazil; ${ }^{3}$ UNIFESP, pathology, sao paulo, Brazil

Background: Primary Sjögren's syndrome (pSS) is an autoimmune disease characterized by lymphocytic infiltration of exocrine glands and other organs, resulting in dry eye, dry mouth, and systemic findings. [1] Objectives: The American College of Rheumatology/AECG group diagnostic criteria for pSS have included three items related to ocular involvement: The Schirmer test type 1, van Bijsterveld score, and Ocular Staining Score (OSS). They are time-consuming and employ costly dyes and instruments. In this context, we analyzed 66 patients with pSS to ascertain correlation between these tests and assess the possibility of streamlining ophthalmologic examination.

Methods: Sixty-six patients (180 eyes) from the Federal University of Sao Paulo outpatient cornea clinic were analyzed prospectively from 2017 to 2018. Those with suspicion of pSS were tested according to the 2016 ACR-EULAR diagnostic criteria. A protocol consisting of the Schirmer, tear-film break-up time (TBUT), van Bijsterveld, and OSS tests was applied to all patients by a cornea specialist. Results were analyzed for correlation and interrater reliability using the kappa coefficient.

Results: Of the 66 patients, 64 were female; 36 were white; median age was $53.3(11,3)$ years. The Schirmer I test was done in 177 eyes, it was positive in $57.6 \%$. TBUT was tested in 175 eyes and was positive in $96 \%$. The van Bijsterveld score was done in 128 eyes and was positive in $61.7 \%$. The OSS was done in 177 eyes and was positive in $68.9 \%$. All four tests could be performed in 128 eyes. The results were confirmed at the same proportions. Correlation between tests was then calculated through the kappa coefficient (Table 1).

Overall agreement was weak $(\kappa=0.340, p<0.001)$. Agreement between TBUT and other tests was particularly poor $(\kappa=0.112-0.144)$. On the other hand, good agreement was observed between the van Bijsterveld score and OSS $(\kappa=0.781, \mathrm{p}<0.001)$. Overall and pairwise kappa coefficients are illustrated in Figure 1.

Conclusion: Schirmer's test without anesthesia has been part of the AECG diagnostic criteria for pSS since 1989. [2].

Our study demonstrates the low sensitivity of the Schirmer I test and the possibility of removing it from the diagnostic criteria. Limitations include our small sample size and lack of comparison group. We hope that, in future, use of objective tests for pSS will become routine ophthalmology practice, reducing costs and facilitating diagnosis.

\section{REFERENCES}

[1] Shiboski CH, Shiboski SC, Raphaèle S, et al. 2016 American College of Rheumatology/European League Against Rheumatism classification criteria for primary Sjögren's syndrome. Ann Rheum Dis 2016;0:1-8.

[2] Workshop on Diagnostic Criteria for Sjögren's syndrome. I. Questionnaires for dry eye and dry mouth. II. Manual of methods and procedures. Clin Exp Rheumatol 1989;7:212-19.

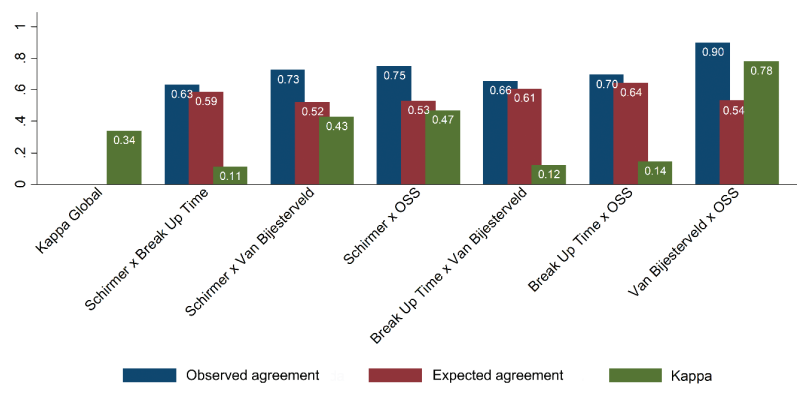

Figure 1. - Overall and pairwise kappa coefficients

Table 1. - Kappa coefficients for classification of primary Sjogren's syndrome

\begin{tabular}{|c|c|c|c|c|c|c|}
\hline & Kappa & $\begin{array}{l}\text { Standard } \\
\text { Error }\end{array}$ & z & $p$ & $\begin{array}{c}\text { Observed } \\
\text { agreement }\end{array}$ & $\begin{array}{l}\text { Expected } \\
\text { agreement }\end{array}$ \\
\hline $\begin{array}{l}\text { Pairwise } \\
\text { comparison }\end{array}$ & 0.340 & 0.036 & 9.42 & $<0.001$ & - & - \\
\hline $\begin{array}{l}\text { Schirmer I x Break- } \\
\text { Up Time }\end{array}$ & 0.112 & 0.041 & 2.76 & 0.003 & $63.28 \%$ & $58.64 \%$ \\
\hline $\begin{array}{l}\text { Schirmer I x Van } \\
\text { Bijsterveld }\end{array}$ & 0.428 & 0.088 & 4.85 & $<0.001$ & $72.66 \%$ & $52.20 \%$ \\
\hline Schirmer I x OSS & 0.469 & 0.088 & 5.35 & $<0.001$ & $75.00 \%$ & $52.93 \%$ \\
\hline $\begin{array}{l}\text { Break-Up Time } x \\
\text { Van Bijsterveld }\end{array}$ & 0.123 & 0.043 & 2.90 & 0.002 & $65.63 \%$ & $60.80 \%$ \\
\hline $\begin{array}{l}\text { Break-Up Time } x \\
\text { OSS }\end{array}$ & 0.144 & 0.046 & 3.15 & 0.001 & $69.53 \%$ & $64.40 \%$ \\
\hline $\begin{array}{l}\text { Van Bijsterveld } x \\
\text { OSS }\end{array}$ & 0.781 & 0.088 & 8.87 & $<0.001$ & $89.84 \%$ & $53.66 \%$ \\
\hline
\end{tabular}

Disclosure of Interests: None declared

DOI: 10.1136/annrheumdis-2019-eular.7280

\section{AB0509 PREVALENCE AND INCIDENCE OF SJÖGREN'S SYNDROME AMONG PATIENTS WITH RHEUMATOID ARTHRITIS IN REAL-WORLD COMMUNITY PRACTICE SETTINGS}

Leticia Ferri ${ }^{1}$, Ying Bao ${ }^{1}$, Sonie Lama ${ }^{1}$, Varshini Rajagopalan ${ }^{2}$, Evo Alemao ${ }^{1}$

${ }^{1}$ Bristol-Myers Squibb, Princeton, United States of America; ${ }^{2}$ Mu Sigma,

Bangalore, India

Background: Sjögren's syndrome (SS) is a rheumatic disease that may coexist with RA, and is often considered a common extra-articular manifes tation of RA. However, few studies have examined the prevalence and incidence of SS in patients with RA in real-world community practice settings. Objectives: To estimate the prevalence and incidence of SS in patients with RA, and to summarise the characteristics of patients with SS associated with RA compared with those of patients with RA alone.

Methods: We analysed data from 1 Jan 2014 to 30 Jun 2018 in a large rheumatology database in the USA, which provides electronic medical record data from 120 community-based rheumatology providers. Adult patients with $\geq 2$ RA diagnoses were identified from 1 Jan 2015 to 30 Jun 2018 (index period). The baseline period was from 1 Jan 2014 to 31 Dec 2014. Among patients with RA, we identified patients with $\geq 2$ SS diagnoses in the index period (prevalent SS patients and patients with $\geq 2$ SS diagnoses in the index period who had not been diagnosed with $S S$ in the baseline period [incident SS patients]). Crude and ageand sex-standardised prevalence and incidence of SS were calculated among patients with RA. Characteristics of prevalent SS patients and patients with RA alone (as a control group) were summarised.

Results: A total of 53,156 patients with RA were identified. Among them we identified 2451 prevalent SS patients and 1450 incident SS patients. The age- and sex-standardised prevalence of SS in patients with RA was $3.48 \%$, and the age- and sex-standardised incidence rate was 0.66 per 100 patient-years. Female patients had a higher prevalence $(5.23 \%$ 
vs $1.68 \%$ ) and incidence (0.96 vs 0.36 per 100 patient-years) of SS than male patients. Compared with other age groups, patients with RA aged 30-49 years had the highest prevalence (3.80\%) and incidence $(0.77$ per 100 patient-years) of SS (Table 1). Compared with patients with RA only, those with both SS and RA were more likely to be female (92\% vs $76 \%$ ), had higher Charlson Comorbidity Index and lower CDAl scores, and were more likely to have prior use of biologic/targeted synthetic DMARDs $(30 \%$ vs $10 \%)$ and conventional DMARDs (48\% vs $18 \%)$ (Table 2).

Conclusion: This study estimated the prevalence and incidence of SS among patients with RA in real-world community practice settings, and provided insights on clinical characteristics of these patients. Patients with both SS and RA have less joint disease activity and greater DMARD exposure than those with RA only. The findings underscore the complexity of SS secondary to RA and highlight the important role of epidemiological research in understanding this condition.

*b/tsDMARDs: abatacept, infliximab, etanercept, adalimumab, certolizumab pegol, golimumab, tocilizumab, rituximab and tofacitinib; cDMARD: MTX, sulfasalazine, azathioprine, tacrolimus, gold thiomalate, leflunomide, aurothioglucose, auranofin, cyclosporine, penicillamine, cyclophosphamide and hydroxychloroquine $b=$ =biologic; $c=$ conventional; IQR=interquartile range; RAPID3=Routine Assessment of Patient Index Data 3; SS=Sjögren's syndrome; ts=targeted synthetic

Acknowledgement: Medical writing: Fiona Boswell, Caudex; funding: Bristol-Myers Squibb

Table 1. Prevalence and incidence of SS in patients with RA

\begin{tabular}{|l|c|c|c|c|c|}
\hline & $\begin{array}{c}\text { Patients } \\
\text { with RA, } \mathbf{n}\end{array}$ & $\begin{array}{c}\text { Prevalent SS } \\
\text { patients, } \mathbf{n}\end{array}$ & $\begin{array}{c}\text { Prevalence, \%, } \\
\text { crude } \\
\text { (standardised }\end{array}$ & $\begin{array}{c}\text { Incident SS } \\
\text { patients, n }\end{array}$ & $\begin{array}{c}\text { IR per 100 PY, } \\
\text { crude } \\
\text { (standardised }\end{array}$ \\
\hline Total & 53,156 & 2451 & $4.61(3.48)$ & 1450 & $0.81(0.66)$ \\
\hline Sex & \multicolumn{5}{|l}{} \\
\hline Female & 40,843 & 2263 & $5.54(5.23)$ & 1331 & $0.98(0.96)$ \\
\hline Male & 12,312 & 188 & $1.53(1.68)$ & 119 & $0.28(0.36)$ \\
\hline Age, years \\
\hline $18-29$ & 1427 & 51 & $3.57(2.70)$ & 36 & $0.74(0.57)$ \\
\hline $30-49$ & 9951 & 512 & $5.15(3.80)$ & 333 & $1.00(0.77)$ \\
\hline $50-69$ & 27,053 & 1327 & $4.91(3.76)$ & 805 & $0.89(0.70)$ \\
\hline$\geq 70$ & 14,725 & 561 & $3.81(3.22)$ & 276 & $0.56(0.46)$ \\
\hline
\end{tabular}

Age and sex-standardised to the 2017 USA population; one patient was excluded from the

calculation due to lack of information on sex

IR=incidence rate; $P Y=$ patient-years; $S S=S j$ gogren's syndrome

Table 2. Characteristics of patients with RA and SS vs RA only

\begin{tabular}{|c|c|c|}
\hline Characteristic & $R A$ and $S S$ & RA only \\
\hline$n$ & 2451 & 50,705 \\
\hline \multicolumn{3}{|l|}{ Age, years } \\
\hline $\mathrm{n}$ & 2451 & 50,705 \\
\hline Median (IQR) & $63.00(15.00)$ & $62.00(20.00)$ \\
\hline Female, $\mathbf{n}(\%)$ & $2263(92.33)$ & $38,580(76.09)$ \\
\hline \multicolumn{3}{|c|}{ Charlson Comorbidity Index score } \\
\hline$n$ & 2451 & 50,705 \\
\hline Median (IQR) & $1.00(1.00)$ & $0.00(0.00)$ \\
\hline \multicolumn{3}{|l|}{ BMI, $\mathrm{kg} / \mathrm{m}^{2}$} \\
\hline $\mathrm{n}$ & 1571 & 10,850 \\
\hline Median (IQR) & $28.13(8.43)$ & $29.09(8.76)$ \\
\hline \multicolumn{3}{|l|}{ CDAl score } \\
\hline $\mathrm{n}$ & 284 & 1262 \\
\hline Median (IQR) & $11.75(16.50)$ & $16.00(17.00)$ \\
\hline \multicolumn{3}{|l|}{ RAPID3 score } \\
\hline$n$ & 127 & 875 \\
\hline Median (IQR) & $9.20(12.60)$ & $12.30(11.20)$ \\
\hline \multicolumn{3}{|l|}{ Comorbidities, $\mathbf{n}(\%)$} \\
\hline Vasculitis & $16(0.65)$ & $34(0.07)$ \\
\hline Lymphoma & $5(0.20)$ & $11(0.02)$ \\
\hline Neuropathy & $65(2.65)$ & $197(0.39)$ \\
\hline Pulmonary fibrosis & $16(0.65)$ & $26(0.05)$ \\
\hline Pulmonary nodules & $9(0.37)$ & $28(0.06)$ \\
\hline \multicolumn{3}{|l|}{ Prior RA treatment, $\mathbf{n}(\%)^{*}$} \\
\hline 0 & 997 (40.68) & $38,317(75.57)$ \\
\hline 1 & $753(30.72)$ & $9037(17.82)$ \\
\hline$\geq 2$ & $701(28.60)$ & $3351(6.61)$ \\
\hline Prior cDMARD, $\mathbf{n}(\%)^{\star}$ & $1173(47.86)$ & $9160(18.07)$ \\
\hline Prior b/tsDMARD, $\mathrm{n}(\%)^{\star}$ & $731(29.82)$ & $5067(9.99)$ \\
\hline
\end{tabular}

Disclosure of Interests: Leticia Ferri Shareholder of: Bristol-Myers Squibb, Employee of: Bristol-Myers Squibb, Ying Bao Employee of: Bristol-Myers Squibb, Sonie Lama Employee of: Bristol-Myers Squibb, Varshini Rajagopalan Consultant for: Bristol-Myers Squibb, Evo Alemao Shareholder of: Bristol-Myers Squibb, Employee of: Bristol-Myers Squibb
DOI: 10.1136/annrheumdis-2019-eular.2130

\section{AB0510 LUNG ULTRASOUND OF PLEURAL IRREGULARITIES IN SUB-CLINICAL PRIMARY SJÖGREN'S SYNDROME- LUNG INVOLVEMENT: A SINGLE CENTRE EXPERIENCE}

Francesco Ferro $^{1}$, Alessandra Bulleri ${ }^{2}$, Elena Elefante ${ }^{3,4}$, Alessandra Tripoli ${ }^{3}$, Marta Mosca ${ }^{3}$, Chiara Baldini ${ }^{3} .{ }^{1}$ University of Pisa, Rheumathology Unit, Department of Clinical and Experimental Medicine, Pisa, Italy; ${ }^{2}$ AOU Pisana, Radiology Unit, Pisa, Italy, ${ }^{3}$ University of Pisa, Rheumatology Unit, Department of Clinical and Experimental Medicine, Pisa, Italy; ${ }^{4}$ University of Siena, Department of Medical Biotechnology, Siena, Italy

Background: Ultrasound of Pleural Irregularities (PI-US) has recently been suggested as a useful tool for the diagnosis and quantification of severity in connective tissue diseases (CTD)-related lung involvement. However, no data are available regarding its role in the sub-clinical phase of primary Sjögren's syndrome (pSS)-related lung involvement.

Objectives: Aim of this study was to describe the role of lung ultrasound analyzing pleural irregularities in asymptomatic pSS-patients in order to early detect lung abnormalities/alterations.

Methods: pSS patients regularly followed-up at our Sjögren's Clinic and asymptomatic for dyspnea and cough, undergoing to CT or HRCT exam for lymphoproliferative and/or neoplastic screening, were included in the study. Demographic, clinical, biological and serological data were collected. PI-US was performed by a single operator using a MyLab ClassC (Esaote), $13-18 \mathrm{MHz}, 5 \mathrm{~cm}$ linear probe. PI was defined as the loss of normal hyperechoic linear pleural contour (score 0-2: normal, minimal and major changes at each intercostal space). PI-US total score represented the sum of partial scores assigned to 6 lung fields ( 2 for the anterior, 2 for postero-superior and 2 for postero-inferior chest surface). CT-abnormal findings, distinguishing typical (interstitial pattern) from atypical lung alterations (non specific findings), were analyzed by an expert radiologist.

Results: 24 pSS patients (AECG criteria), $20 \mathrm{~F}: 4 \mathrm{M}$, mean age $=58$ \pm 12.2 yrs, mean follow-up duration $8.6 \pm 12$.2 yrs, were included in the study. All patients were positive for ANA, 21/24 for anti-Ro/SSA, 15/24 for Rheumatoid Factor (RF) and 6 of them for cryoglobulins.

Four patients $(16.67 \%$ ) had a previous history of pSS-related lymphoproliferative disorder

None of the included patients reported cough or dyspnoea and the thoracic examination did not arise any abnormalities suggestive for lung disases.

The mean PI-US total and postero-inferior partial score resulted 22.75 \pm 19.72 and $8.29 \pm 8.60$ respectively. CT/HRCT resulted normal in $9 / 24$ patients $(37.5 \%)$ and showed abnormal findings in $15 / 24(62.5 \%)$. The latter consisted of non- Interstitial Lung Disease (ILD) alterations in 13/15 cases (i.e 13/13 fibrotic striae and/or micro/macronodularities, 5/13 disventilatory striae and/or medium lobe syndrome, 3/13 bronchiectasias and/or bronchioloectasias and 3/13 thin-walled cysts/atypical emphysema). In 2/15 patients a new diagnosis of Interstitial Lung Disease (ILD) was made with patients presenting a typical NSIP-pattern. Both the mean PI-US total score and the postero-inferior partial score resulted significantly higher in patients with abnormal CT/HRCT compared to those with normal CT findings $(p=0.003$ and $p=0.001$ respectively). On the contrary, PI-US total and partial scores were not significantly different between ILD and non ILD pSS patients $(p=0.103)$.

Conclusion: this study highlights the potential usefulness of PI-US as a sensitive, non invasive tool for the diagnosis of sub-clinical early lung alterations in pSS.

Disclosure of Interests: Francesco Ferro: None declared, Alessandra Bulleri: None declared, Elena Elefante: None declared, Alessandra Tripoli: None declared, Marta Mosca Paid instructor for: GlaxoSmithKline, Lilly, UCB, Chiara Baldini: None declared DOI: 10.1136/annrheumdis-2019-eular.5973 